\title{
Linfoma difuso extra nodal multicéntrico de células grandes y pequeñas en un canino Reporte de caso
}

\section{A case report concerning diffuse large and small cell extranodal lymphoma in a dog}

\author{
Diego A. Riveros-Pinilla1, Daniel F. Polanco-Polanco² \\ Julieta E. Ochoa-Amaya ${ }^{3}$ \\ ${ }^{1,2}$ Estudiantes Universidad de los Llanos, Facultad de Ciencias Agropecuarias y Recursos Naturales \\ ${ }^{3} \mathrm{MVZ}$, MSc, Profesor Patología Animal, Escuela de Medicina Veterinaria y Zootecnia \\ Email: julietaeochoa@yahoo.es
}

Recibido: Noviembre 3 de 2010. Aceptado: Mayo 23 de 2011

\section{RESUMEN}

Un canino, hembra, de raza criolla de 6 años de edad, fue llevado a la Clínica Veterinaria de la Universidad de los Llanos, el propietario no reporta planes de vacunación ni enfermedades anteriores. Al examen clínico se encontró una mala condición corporal (2/5), ausencia de incisivos superiores e inferiores, alopecia bilateral en nuca, cuello y dorso, dermatitis húmeda en la cruz, hiperqueratosis, hiperpigmentación, ligera claudicación del miembro anterior y posterior izquierdo. Se eutanasia al paciente, se realiza la necropsia y se toman muestras de tejidos los cuales se fijaron en formalina buffer al $10 \%$ que fueron enviados al laboratorio de histopatología animal (Universidad de los Llanos). Las muestras se procesaron mediante métodos rutinarios para microscopía óptica. Los cortes histológicos de 3-4 mm de grosor se colorearon con Hematoxilina-Eosina (H\&E), método de Azul de toluidina y coloración del ácido periódico de Schiff (PAS). El reporte de necropsia remitido al laboratorio de histopatología animal refería los siguientes hallazgos macroscópicos: una masa en la mucosa uretral de $3 \times 1.5 \mathrm{~cm}$, lisa al tacto con color blanquecino y en la corteza renal izquierda macroscópicamente un foco blanco, adicionalmente congestión intestinal con presencia de Toxocara canis y Ancylostoma caninum. Al análisis histopatológico se diagnostico un linfoma de células grandes y pequeñas ubicado en la mucosa uretral y en la corteza renal, cuya descripción microscópica es de células linfoides dimórficas con núcleos excéntricos y de diferentes tamaños, algunos con binucleación. Histopatológicamente se diagnostica linfoma de células grandes y pequeñas multicéntrico ubicado en la mucosa uretral y corteza renal, se descarta el mastocitoma por medio de la coloración de Azul de toluidina pues no se evidencio metacromasia en los gránulos citoplasmáticos.

Palabras claves: Linfoma extranodal difuso, canino.

\section{ABSTRACT}

A6-year old bitch was taken to the Universidad de los Llanos' Veterinary Clinic; the dog's owner did not report vaccination history or past illness. Clinical examination revealed a poor physical condition (2/5), the absence of 
upper and lower incisors, bilateral alopecia in the nape, neck and back, wet dermatitis on the withers, hyperkeratosis, hyperpigmentation and a mild limp affecting the fore and hind limbs. Euthanasia was performed, followed by necropsy; tissues were sampled, fixed in $10 \%$ formalin buffer and sent to the Animal Histopathology Laboratory (Universidad de los Llanos). The samples were processed using routine optical microscopy methods; 3-4mm thick histological sections were stained with haematoxylin and eosin (H\&E), toluidine blue and periodic acid-Schiff (PAS) staining methods. The necropsy report sent to the Animal Histopathology Laboratory (Universidad de los Llanos) reported the following macroscopic findings: a whitish, smooth to the touch, $3 \times 1.5 \mathrm{~cm}$ mass in the urethral mucosa, and a white focus in the left renal cortex, intestinal congestion with the presence of Toxocara canis and Ancylostoma caninum. A large and small cell lymphoma was diagnosed in the urethra and renal cortex mucosa during histopathological analysis. Microscopic examination reported dimorphic lymphoid cells having different sized eccentric nuclei, some of them binucleated. Multicentric lymphoma of big and small cells located in the renal cortex and urethral mucosa was diagnosed; mastocytoma was discarded by blue toluidine method because there was no evidence of a metacromasy in the cytoplasmic granules.

Key words: Diffuse extranodal lymphoma, canine.

\section{INTRODUCCIÓN}

El linfoma es la neoplasia primaria del tejido linfoide y en los perros $(74,1 \%)$ como en los gatos es el más frecuente de los tumores hemolinfaticos (Ferreira de la Cuesta y Pedraza, 2003; Raskin et al, 2004; Valli et al, 2011). Ni el género ni la castración fueron factores predisponentes para el desarrollo de linfoma, ni para la presentación del mismo; sin embargo hubo una asociación significativa entre el tipo de tumor, la localización y el fenotipo molecular, esto quiere decir, que en linfomas extraganglionares y en la mayoría de las leucemias su origen es de las células $\mathrm{T}$, lo mismo que todos los tumores de células plasmáticas su origen es de células B (Modiano et al, 2005). En los estudios de epidemiología de linfoma canino; las razas Bóxer tuvieron un riesgo 4 veces más alto comparado con las otras razas estudiadas (Modiano et al, 2005), seguidos por las razas Terriers Escoceses, Pastores Alemanes, Caniches y la evidencia reciente sugiere una alta incidencia en los Golden Retrievers (Moore, 2007), no así en individuos Pomeranianos que tuvieron un riesgo 10 veces más bajo con relación a las otras razas (Modiano et al, 2005). El hallazgo físico más común en perros con linfoma son las adenopatías periféricas, que suelen ser generalizadas, pero se pueden localizar a un solo ganglio linfático o a una región del cuerpo. Participación de otros órganos, tales como médula ósea, bazo, hígado o los huesos son una indicación de enfermedad avanzada. El compromiso de otros sitios diferentes a los primarios es rara en perros (extranodal) (Moore, 2007).

La gran cantidad de los subtipos de linfomas en sitios extranodales, la variación en la morfología, en el inmunofenotipo, en la genética y en las características clínicas dentro y entre esas entidades y las dificultades en distinguir esos linfomas de infiltrados linfoides reactivos $u$ otras neoplasias y el significado clínico diferente de los linfomas con compromiso de sitios primarios versus sitios secundarios extranodales, constituyen un gran desafío en el diagnóstico (Bacon, 2009), en el tratamiento y pronóstico (Marconato 2011) de los linfomas caninos, pues hay una amplia gama de respuesta al tratamiento y la supervivencia se relaciona al hecho de que el linfoma no es una entidad homogénea (Ponce et al, 2004).

Debido a que el linfoma es una enfermedad sistémica, la quimioterapia sistémica es la modalidad terapéutica más adecuada (Valli et al, 2011). La cirugía no es una modalidad de tratamiento de elección porque ésta enfermedad es sistémica, en unos pocos casos la cirugía puede ser utilizada como cuando el grado del linfoma está en estado I, los nódulos solitarios pueden ser extraídos. Las células de linfoma son sensibles a la quimioterapia y las tasas de remisión completa es elevada cuando los pacientes son tratados con quimioterapia convencional y éstos mantienen una 
buena calidad de vida, entonces el tratamiento puede proporcionar la resolución de muchos signos y anomalías, los agentes más efectivos son doxorubicina, L-asparaginasa, vincristina, ciclosfosfamida y prednisolona (Ettinger 2003; Marconato 2011). La radiación es una modalidad terapéutica local y es así mismo limitada para el tratamiento del linfoma, es indicada para el estado de linfoma tipo I, linfoma nasal, linfoma del sistema Nervioso central y lesiones de hueso solitarias (Ettinger 2003).

En caninos, la etiología de los linfomas se considera multifactorial, ya que no se ha identificado un agente etiológico aislado, se cree en una etiología de origen genético, al menos en algunos perros (trisomía del cromosoma 13), además, se han considerado causas ambientales e infecciosas. Es así, como en un estudio realizado en los perros que vivían en un entorno urbano, el linfoma fue la neoplasia más común y se asoció al uso de sustancias químicas por los propietarios, específicamente ácido 2,4diclorofenoxiacético $(2,4-\mathrm{D})$, pinturas, asbestos o disolventes, o la radiación, así como a la exposición a campos electromagnéticos los cuales predispusieron a un mayor riesgo para padecer el linfoma canino (Moore, 2007).

El linfoma puede presentarse en varias formas anatómicas (Aceña, 2008):

1. Linfoma multicéntrico: caracterizado por linfadenomegalia generalizada y es la forma mas frecuente en el perro (Raskin et al, 2004; Aceña, 2008), con el $93 \%$ en un estudio hecho en la Universidad de Antioquia durante 30 años (Ferreira de la Cuesta y Pedraza, 2003), también compromete bazo e hígado (Raskin et al, 2004). La linfadenopatia es simétrica, se nota cuando aun el animal está en relativamente buena condición (Ettinger 2003; Valli, 2007).

2. Linfoma mediastínico: afección de los nódulos linfáticos mediastínicos craneales.

3. Linfoma digestivo o alimentario: afección del aparato digestivo (intestino preferentemente) con 7 $\%$ al tipo digestivo según el estudio epidemiológico hecho durante 30 años en la Universidad de Antioquia en caninos (Ferreira de la Cuesta y Pedraza, 2003). Se presenta con vómito y diarrea a menudo sanguinolenta (Valli, 2007), hay ulceración en la mucosa en el $50 \%$ de los casos entéricos y tienen algún grado de anemia acompañado por una moderada a marcada leucocitosis neutrofílica (Ettinger 2003; Valli, 2007).

4. El término linfoma extra nodal se utiliza para aquellos linfomas cuya localización no está incluida por las otras agrupaciones anatómicas, por ejemplo renal, nasofaringe, ocular, neural, cutáneo (Ettinger 2003), SNC (Birchard, 1994; Ettinger 2003, Raskin et al, 2004; Aceña, 2008).

En los riñones de todas las especies animales el linfoma es uno de los tumores más comunes (Meuten, 2002), puede presentarse como manifestación primaria de linfoma, o puede ser un componente de linfoma multicéntrico (Borgerson, 2003). Cerca del $50 \%$ de los perros tienen algún grado de compromiso renal y proporcionalmente incapacidad de función, debido a la infiltración tumoral o a la hipercalcemia que es más alta, por lo que estos animales padecen de polidipsia, poliurea y están usualmente en estado de colapso (Valli, 2007). El linfoma no es confinado solamente a riñón y el tejido tumoral podrá ser localizado en nódulos linfoides y otros tejidos linfoides. La neoplasia puede causar azotemia por destrucción del $75 \%$ del parénquima o por única localización en la vía excretora obstruyendo la salida de la orina. Ellos pueden ser asociados con anemia no regenerativa, policitemia o hipercalcemia (Meuten, 2002).

Los tumores uretrales son raros encontrarlos en los caninos y estos ocurren en perros muy viejos con una edad promedio de 10,4 años y son los Beagles los que mayormente los padecen. En una tercera parte de los casos aproximadamente ocurren metástasis, éstas con mayor frecuencia a los nódulos linfáticos regionales. La incidencia de presentación de los tumores de la vejiga urinaria y la uretra es aproximadamente un $0,5-1,0 \%$ de todas las neoplasias caninas, entre ellos tenemos los tumores primarios ( $96 \%$ ) como carcinomas de células transicionales, carcinomas escamo celulares, adenocarcinomas y como neoplasia secundaria el linfoma (4\%) (Meuten, 2002). 
En los linfomas la población heterogénea de linfocitos maduros es sustituida por una población mono mórfica de numerosas células linfoides generalmente inmaduras. Los criterios citológicos más útiles a considerar se basan en las características nucleares de tamaño, forma, membrana nuclear, cromatina, nucléolos y mitosis atípicas. En los caninos se utiliza un sistema de clasificación como fórmula de trabajo basado en la usada por el Instituto Nacional del Cáncer, en cuanto a linfomas no Hodking en humanos, por extrapolación los criterios morfológicos son útiles para establecer un pronóstico de los mismos (de Buen de Argüero, 2001, Guija de Arespacochaga et al, 2007; Valli et al, 2011), éste tipo de linfoma es raro que se presente en los animales, sin embargo ha sido reportado en perros con alguna frecuencia (Ferreira de la Cuesta, 2003; Guija de Arespacochaga et al, 2007).

Aunque existen diferentes tipos histológicos e inmunofenotípicos de linfoma, la mayoría de las veces están formados por linfocitos inmaduros de gran tamaño celular ( 2 a 3 veces el tamaño de un glóbulo rojo), citoplasma intensamente basófilo y núcleo con nucléolos evidentes (linfomas de alto grado). En ocasiones, la población linfoide está formada por linfocitos pequeños ( 1 a 1,5 veces el tamaño de los glóbulos rojos) con escasas mitosis (linfomas de bajo grado) (Aceña, 2008). Para clasificar el inmunofenotipo de los linfomas se realiza la Inmunohistoquímica con anticuerpos CD3 para identificar células T; anticuerpos CD79a y CD20 para identificar las células B, CD45y CD18 (panleucocítico), MUM1 para células plasmáticas (Guija de Arespacochaga et al, 2007; Valli et al, 2011).

El tamaño de los linfocitos es clave para la clasificación de los linfomas, de acuerdo a ello, los linfomas se clasifican en linfoma de células pequeñas cuando los núcleos son algo mayores que un eritrocito, la cromatina es dispersa y densa, el nucléolo es pequeño e inaparente, la margen celular es distinta, entre ellos tenemos el linfoma de las zonas $\mathrm{T}(\mathrm{TZL})$, la leucemia crónica linfoblástica (CLL), el linfoma linfocitico de células pequeñas (SLL) (Ramos Vara, 2008).
El linfoma intermedio, tiene los núcleos del diámetro de 1,5 a 2 eritrocitos, son redondos u ovales, con nucléolos pequeños y múltiples, espacio claro para cromatina, márgenes celulares distintos, entre ellos tenemos el linfoma like de Burkitt (BKL) (Ramos Vara, 2008).

Linfomas con cromatina uniformemente dispersa y nucléolo difícil de ver, mitosis mal definidas como el linfoma linfoblástico (LB) (Ramos Vara, 2008).

Linfoma de zona marginal (MZL) con cromatina periférica y un único y prominente nucléolo central, pocas mitosis, citoplasma abundante (Ramos Vara, 2008).

El Linfoma centroblástico (CB), con células grandes, donde el núcleo es de diámetro mayor de dos eritrocitos, redondo $u$ oval, con cromatina fina $o$ gruesa, granular o ramificada y periférica, citoplasma de volumen y tinción moderadas. El núcleo es uniforme con nucléolos múltiples adyacente a la membrana nuclear (Ramos Vara, 2008).

Linfoma tipo inmunoblastico (IB), con núcleo uniforme y con un único nucléolo central (Ramos Vara, 2008), es un tumor difuso. Una variante polimorfa del tumor presenta la mitad de la población neoplasica constituida por linfocitos pequeños de núcleo identado, con citoplasma escaso pero también basofílico, puede haber grupo de macrófagos epitelioides (Ferreira de la Cuesta, 2003).

El linfoma anaplásico de células grandes (ALCL), con núcleo de contorno muy irregular (ejemplo, reniforme, elongado, herradura de caballo) (Ramos Vara, 2008).

El linfoma de células mixtas; donde la arquitectura es difusa con estroma fibrovascular delicado, bandas ocasionales fibrosas y focos de necrosis isquémica. La población neoplasica es predominantemente de células pequeñas e intermedias con núcleo redondo (Ramos Vara, 2008).

Hay un número reducido y variable de células grandes con núcleo redondo o identado, algunas células 
binucleadas, cromatina ramificada y periférica, uno a dos nucléolos centrales y prominentes, citoplasmaabundante con límites celulares distintos (Ramos Vara, 2008).

Linfoma de células $B$ rico en células T (TCRLBCL), donde las células son pequeñas e intermedias y fenotípicamente son linfocitos $T$ y las grandes son linfocitos B, (Ramos Vara, 2008).

Entre los linfomas extra nodales está el de tipo linfoide mixto periférico (PTLC) donde frecuentemente hay proliferación focal, es subcutáneo no está encapsulado, es de células linfoides mixtas, las que son caracterizadas por baja progresión y puede llegar a un linfoma de células $T$ multicéntrico, intratable terapéuticamente, el cual forma lesiones sólidas que semejan otras proliferaciones de células T, por ejemplo linfoma de células $B$ rica en células $T$ y linfoma angioinmunoblastico, ellos tienen una fina red fibrovascular progresiva. Citológicamente, esos tumores son remarcadamente heterogéneos conteniendo células plasmáticas y linfocitos atípicos de pequeños a muy grandes, con un prominente nucléolo y citoplasma teñido con CD3 (Valli et al, 2002).

En el linfoma de células grandes y pequeñas hendidas, su citoplasma es moderado, el núcleo es inmaduro, la cromatina es gruesa y posee de uno a dos nucléolos y un índice mitótico variable, con una clasificación de malignidad intermedia (de Buen de Argüero, 2001).

\section{Presentación del caso}

\section{Evaluación del paciente}

\section{Anamnesis}

Un canino, hembra, de raza criolla de 6 años de edad, fue llevado a la clínica veterinaria de la Universidad de los llanos, el motivo de la consulta fue la presentación de alopecia bilateral en nuca, cuello, tórax y engrosamiento de la piel localizada en dorso y miembros, lo mismo que dermatitis húmeda en la cruz, hiperqueratosis e hiperpigmentación; el propietario no reporta planes de vacunación ni enfermedades anteriores.

Hallazgos al examen clínico

Al examen clínico se encontró una mala condición corporal (2/5), ausencia de incisivos superiores e inferiores, ligera claudicación del miembro anterior y posterior izquierdo y la presencia de una masa en la mucosa uretral.

\section{Ayudas diagnósticas}

Al paciente le fue tomado un hemograma en el cual se evidenció anemia normocítica no regenerativa moderada y linfocitosis absoluta con eosinofilia absoluta (véase Tabla 1).

Tabla 1. Resultados del Hemograma del Paciente

\begin{tabular}{cccc}
\hline VARIABLE & UNIDADES & RESULTADO & V.R. \\
\hline Hematocrito & $\%$ & 25 & $37-54$ \\
Rto. plaquetas & $\times 10^{3} \mathrm{x} \mathrm{mm}^{3}$ & 226 & $160-430$ \\
Rto. G. Rojos & $\times 10^{6} \times \mathrm{mm}^{3}$ & 3.7 & $5.8-8.6$ \\
V.C.M & $\mathrm{fl}$. & 66 & $62-74$ \\
Neutrófilos & $\%$ & 52 & $60-77$ \\
Linfocitos & $\%$ & 30 & $13-27$ \\
Eosinófilos & $\%$ & 10 & $2-10$ \\
\# Neutrófilos & $\times 10^{3} \times \mathrm{mm}^{3}$ & 9.1 & $3.0-11.5$ \\
\# Linfocitos & $\times 10^{3} \mathrm{x} \mathrm{mm}^{3}$ & 6.65 & $10-4.8$ \\
\# Eosinófilos & $\times 10^{3} \mathrm{x} \mathrm{mm}^{3}$ & 1.75 & $0.1-1.25$ \\
\hline
\end{tabular}


E igualmente le fue practicado un Coprológico y un raspado de piel (véase Tabla 2).

Tabla 2. Resultados de Coprológico y raspado de piel del Paciente

\begin{tabular}{ll}
\hline EXAMEN & RESULTADO \\
\hline Coprológico & Ancylostoma caninum \\
& Toxocara canis \\
Raspado de piel & + Hongos \\
& Ácaros \\
\hline
\end{tabular}

El animal fue donado a la cátedra de Patología debido a su estado de deterioro donde le fue realizada la eutanasia con consentimiento del propietario y posterior necropsia donde se toman muestras de tejidos que luego son fijados en formalina tamponada al $10 \%$ los que fueron enviados al laboratorio de histopatología animal.

\section{RESULTADOS}

\section{Exámen post mortem}

Hallazgos macroscópicos

Como hallazgos representativos se encontraron: una masa en la mucosa uretral de aproximadamente 3 $\mathrm{cm} \times 1.5 \mathrm{~cm}$, lisa al tacto, de color blanquecino, en el riñón izquierdo un cambio de coloración, con una zona pálida blanquecina de aproximadamente 0.5

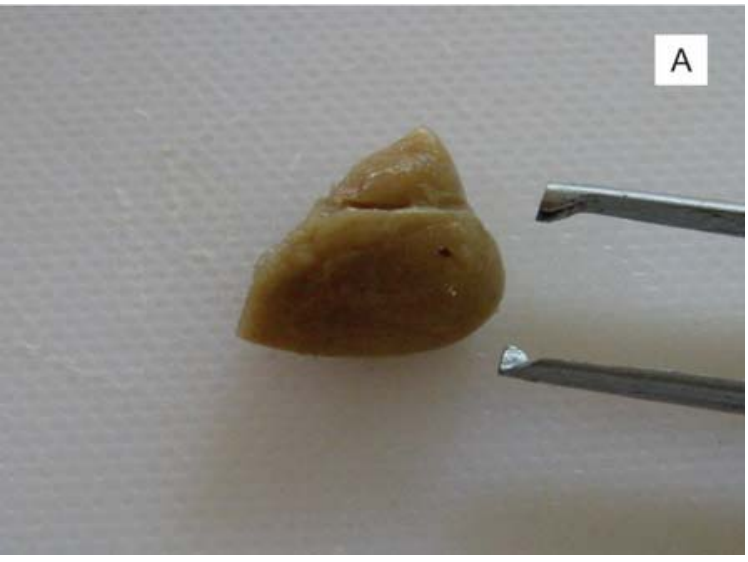

$\mathrm{cm}$. en la corteza renal (véase Figura 1). El hígado se encontró aparentemente normal sin alteraciones de superficie ni coloración. De forma generalizada, a lo largo de todo el intestino delgado hubo congestión de la mucosa intestinal, así como la presencia de parásitos Toxocara canis.

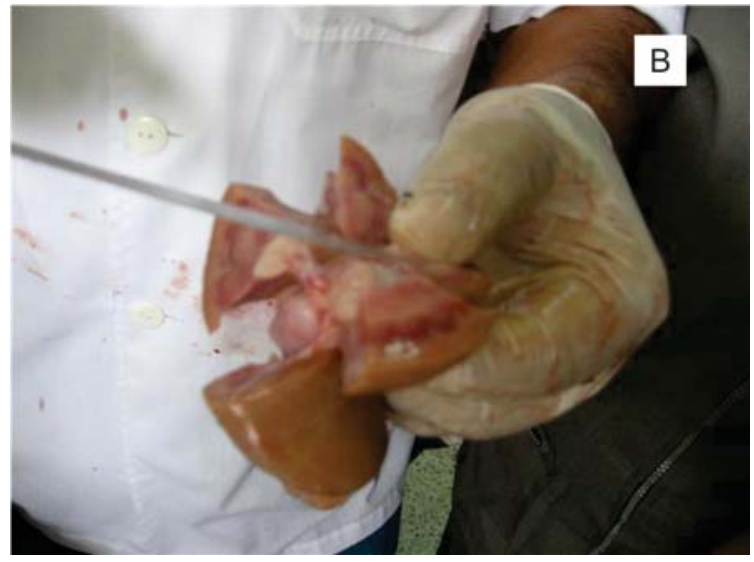

Figura 1. Presencia de masa en la mucosa uretral, de aproximadamente $3 \mathrm{~cm} \times 1.5 \mathrm{~cm}$, lisa al tacto, de color blanquecino, (A). Corteza del riñón izquierdo con cambio de coloración color blanquecino de aproximadamente $0.5 \mathrm{~cm}$, (B) 


\section{Hallazgos Histopatológicos}

Al examen histopatológico con la coloración de Hematoxilina eosina ( $\mathrm{H}-\mathrm{E})$ se evidenció en la uretra la neoplasia compuesta por una población de células de morfología redondeada dimórficas, asociadas a la submucosa, linfocitos grandes y pequeños con los núcleos que varíaron de tamaño, algunos excéntricos y ocasionalmente células con binucleación (véase Figuras $2 \mathrm{~A}$ y $2 \mathrm{~B}$ ) en los aumentos de $4 x$ y $40 x$ respectivamente, clasificándose como linfoma de células grandes de tipo inmunoblastico con linfocitos pequeños. Fue posible observar en el Linfoma uretral, pleomorfismo celular, mega núcleos (apuntador), (H-E) 40x (véase Figura 2C) y una figura mitótica (apuntador), (H-E) 40x, (véase Figura 2D). En el hígado se observó infiltración de células mononucleares (véase Figura 2E) H-E 4x y cambios degenerativos como vacuolizaciones citoplasmáticas en los hepatocitos (véase Figura 2F) H-E 10x, dicho órgano se evaluó con las coloración de acido Peryódico de Schiff (PAS) y se confirmaron las acumulaciones de glucógeno hepático, foto no mostrada en el artículo. Dentro del diagnóstico diferencial se enlisto el
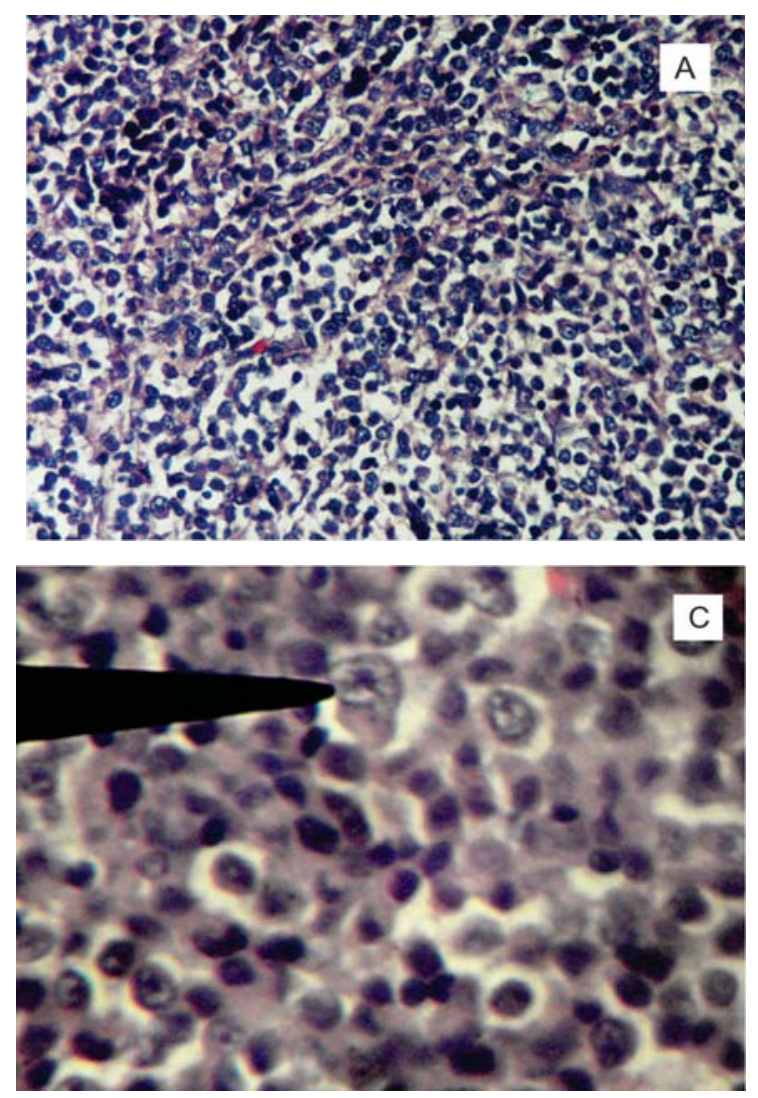

mastocitoma, que pertenece a los tumores de células redondas, por lo que se realizó la coloración de Azul de toluidina con el fin de observar metacromasia en los gránulos citoplasmáticos de las células neoplasicas, pero no dio positivo para ésta histoquímica, lo cual nos permitió descartar el mastocitoma y diagnosticar un linfoma, para posteriormente hacer la clasificación del mismo de acuerdo a su morfología y comparar el núcleo de las células neoplásicas linfoides con el tamaño de un glóbulo rojo y poder emitir el diagnóstico histopatológico de linfoma de células grandes de tipo inmunoblastico con linfocitos pequeños. Histopatológicamente se observo un riñón con infiltración intersticial de células inflamatorias de tipo mononuclear, células grandes basófilas con escaso citoplasma compatibles con linfocitos, además de áreas de necrosis, Azul de toluidina 40x, (véase Figura G). Se observa la similitud existente dentro de la morfología de infiltrado encontrado tanto en riñón como en la neoplasia, linfocitos más grandes de lo normal con cromatina dispersa H-E 40x, (véase Figura H).
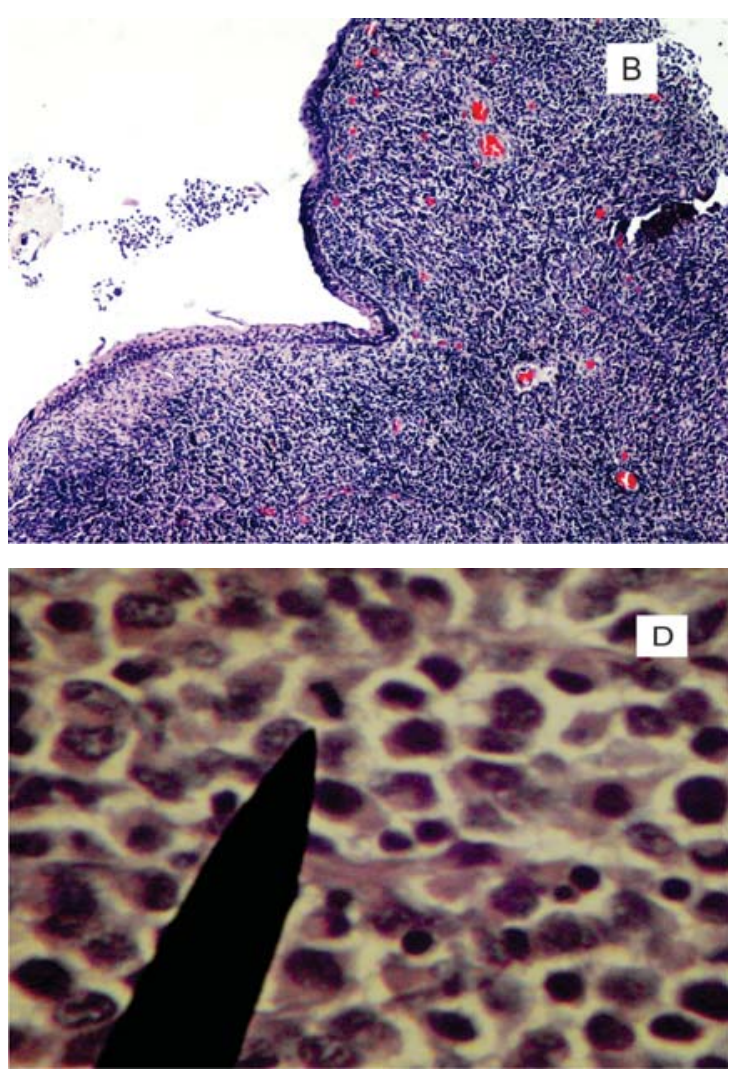

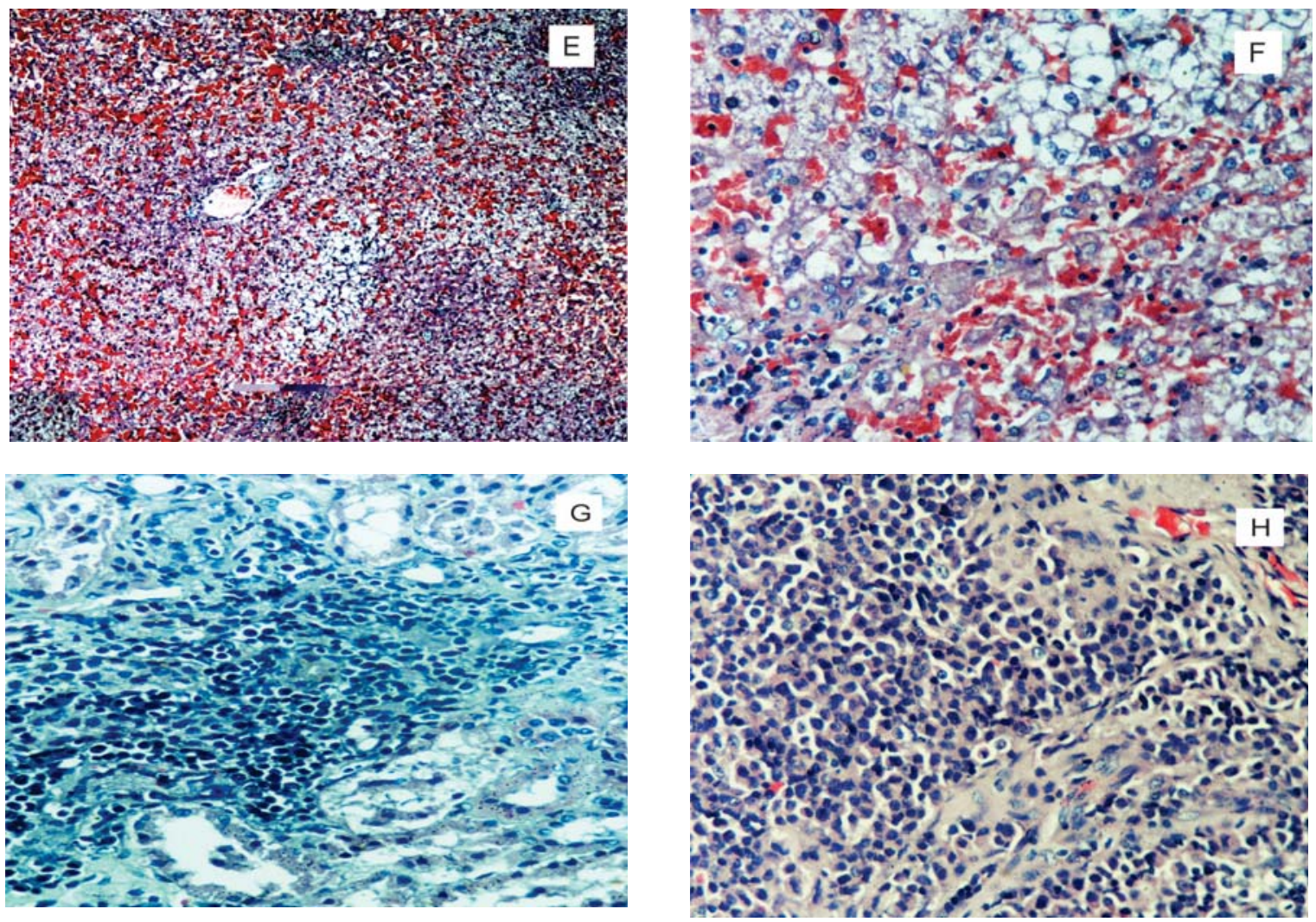

Figura 2. Uretra, se observa población celular con morfología redondeada asociada a la submucosa, (H-E) 4x, (A). Uretra, población de células dimórficas, algunas células con binucleación, anisocariosis, núcleos excéntricos (H-E) 40x, (B). Linfoma uretral, pleomorfismo celular, mega núcleos (apuntador), (H-E) 40x, (C). Linfoma uretral, figura mitótica, (apontador) (H-E) 40x, (D). Hígado, con zonas de infiltración de células mononucleares (circulo) (H-E) 4x, (E). Cambios degenerativos en el citoplasma de los hepatocitos (H-E) 10x, (F). Riñón con infiltración intersticial de células inflamatorias de tipo mononuclear, células grandes basófilas con escaso citoplasma compatibles con linfocitos además de áreas de necrosis, (Azul de toluidina) 40x, (G). Se observa la similitud existente dentro de la morfología de infiltrado encontrado tanto en riñón como en la neoplasia. Linfocitos más grandes de lo normal con cromatina dispersa. (H-E) 40x, (H).

\section{DISCUSIÓN}

Entre los diagnósticos diferenciales que se enlistaron estaban el linfoma, mastocitoma, el histiocitoma, el tumor venéreo transmisible.

Cuando se hizo la coloración con azul de toluidina en el laboratorio de Histopatología de la Universidad de Los Llanos no se evidenció metacromasia de los gránulos citoplasmáticos de las células infiltradas en el riñón, por lo que se descarto el mastocitoma pues es característico de los mastocitomas la afinidad que tienen por los proteoglicanos ácidos almacenados en los gránulos haciéndolos visibles (Landon y Seguin, 2003;
Ramos Vara, 2008) y la evidencia tanto histopatológica y de morfología celular así como la distribución tisular no fueron compatibles con dicha neoplasia, siendo ausentes los cordones densos empacados de células con citoplasma basófilo granular y de células eosinófilas acompañantes (Jones T, Hunt R, King N. 1997) lo mismo que la ausencia de las lesiones propias del mastocitoma tales como degeneración fibrinoide e hialinización de pequeñas arteriolas, acompañada de vasculitis expresada como infiltración eosinofílica perivascular (Ferreira de la Cuesta G, 2003), lo que permitió descartarlo y 
encausar el diagnostico a un Linfoma difuso extranodal de células grandes de tipo inmunoblastico y linfocitos pequeños. También se eliminó el proceso inflamatorio puesto que además de que en él se presenta una población mixta de linfocitos incluyendo células pequeñas, bien diferenciadas, con numero muy bajo de linfocitos reactivos, células plasmáticas y linfoblastos (Borgesson, 2003); el linfoma del paciente del estudio se caracterizó por una población de células inmaduras grandes mezcladas con linfocitos pequeños.

Neoplasias de células redondas incluyendo malignidades histiocíticas y el plasmacitoma podrían tenerse en cuenta, sin embargo el sarcoma histiocítico e histiocitosis maligna consisten de una población de histiocitos con un citoplasma abundante y altamente vacuolado y un núcleo excéntrico (Borjesson, 2003) lo que no se observó en el paciente de estudio.

El histiocitoma fue descartado debido a que se presenta principalmente en animales jóvenes menores de dos a tres años de edad (Ramos Vara, 2008), no siendo así la edad del animal de estudio, además de esto el histiocitoma cutáneo canino es un tumor de crecimiento rápido, entre una a cuatro semanas, su crecimiento es muy acelerado, su connotación es benigna aunque su actividad mitótica es generalmente alta (Ferreira de la Cuesta, 2003); encontrándose hasta diez figuras mitóticas por campo en aumento de 400x, características que no fueron evidentes en la neoplasia estudiada. Además, su presentación es principalmente cutánea. Aunado a esto, la metástasis en los histiocitomas se informó como nula (Ferreira de la Cuesta G, 2003; Barragan et al, 2006; Ramos Vara, 2008) y en el paciente de estudio se presentó la neoplasia en más de un lugar.

Las dos terceras partes de la uretra de la hembra canina es lineada por epitelio escamoso y una tercera parte, la proximal es lineada por epitelio transicional, por lo que descartamos el linfoma como neoplasia primaria en la uretra (Meuten, 2002), según los reportes de presentación de neoplasias en tracto urinario, es mas común que en el riñón se presente linfoma (Meuten, 2002) y el linfoma renal puede presentarse como manifestación primaria, o puede ser un componente de linfoma multicéntrico (Borgerson, 2003), por lo tanto el linfoma del paciente tuvo mas de un origen, en el tejido linfoide asociado a la mucosa de la uretra y al riñón por lo que lo clasificamos como un linfoma multicéntrico.

El conteo sanguíneo periférico no es sensible en la identificación del linfoma canino; el $21 \%$ de los perros afectados tienen linfocitosis y el $25 \%$ tienen linfopenia. Al tiempo del diagnostico, por encima del $57 \%$ de los perros pueden ser leucémicos. El conteo sanguíneo completo puede documentar concurrentemente citopenias, incluyendo anemia, trombocitopenia, y leucopenia (Raskin et al, 2004). En el estudio se observo que el paciente tuvo anemia normocítica moderada no regenerativa y está dentro del rango del $21 \%$ de los perros afectados por linfoma que poseen linfocitosis. Este tipo de anemia normocítica, es relativamente asociada al desarrollo del síndrome paraneoplásico con el que cursaba el animal, en humanos, la anemia es una complicación frecuente en los pacientes con cáncer, hasta un $70 \%$ de las Neoplasias Hematológicas y un $62 \%$ de los Tumores Sólidos presentaron Anemia durante algún momento evolutivo de la enfermedad (Oltra, 2007). También se ha llamado "anemia de la inflamación", ya que la principal causa es un proceso inflamatorio de largo tiempo de evolución, que se presenta en las enfermedades crónicas como el cáncer (Patino, 2009).

Es importante relacionarla con diferentes factores de procesos crónicos que se presentan durante el Sindrome Paraneoplasico (SPN) como son: la disminución de la reutilización del hierro en la médula ósea, la hipoplasia eritroide en médula ósea, moderada disminución de la vida media del hematíe, disminución de los niveles de eritropoyetina y el incremento de la actividad fagocítica de los macrófagos con liberación excesiva de citocinas (Interleucina-1, Factor de Necrosis Tumoral, entre otras) que inhiben la proliferación de la línea eritroide e interfieren en la 
relación normal entre las concentraciones de eritropoyetina y el hematocrito (Oltra, 2007). E igualmente el paciente presentó una eosinofilia la

\section{CONCLUSIÓN}

Queda impreciso definir cual es el sitio primario de la neoplasia si es el riñón o es la uretra, lo cierto es que es poco frecuente encontrar linfoma en la

\section{AGRADECIMIENTOS}

A la Clínica Veterinaria junto con la doctora Anita Isabel Roque R, al Laboratorio Clínico y al laboratorio de Histopatología de la Universidad de los Llanos,

\section{REFERENCIAS}

Aceña M. Introducción al diagnóstico citopatológico. En: Iregui CA, Rey AL, Botero L, editores. Memorias 1. Bogotá, Colombia: Curso Seminario Internacional de Patología Veterinaria. 2008. p. 165.

Borgersen D. Renal Citology. Vet Clin Small Anim 2003; 33: 130-133.

De Buen de Argüero N. 2001. Citología de órganos y tejidos. En: Citología Diagnostica veterinaria. Edit. El Manual Moderno, México, D. F. p. 83-84.

Ettinger SN. Principles of treatment for canine lymphoma. Clinical Techniques in Small Animal Practice 2003;18(2): 92-97.

Ferreira de la Cuesta G, Pedraza F. Caracterización y análisis de las neoplasias registradas en el Laboratorio de Patología Animal de la Universidad de Antioquia durante 30 años (1968-1998). En: Ferreira de la Cuesta G. 2003. Patología Veterinaria. Editorial Universidad de Antioquia, Medellín (Colombia), p. 580581.

Ferreira de la Cuesta G. 2003. Patología Veterinaria. Editorial Universidad de Antioquia, Medellín (Colombia), p. 136-139. cual pudo ser debida a la infestación parasitaria (Ancylostoma caninum, Toxocara canis) (Meyer y Harvey 2000).

uretra y si lo hay está asociado al tejido linfoide de la mucosa uretral por lo cual se clasifica como un linfoma extra nodal de células grandes y pequeñas multicéntrico porque tiene más de un origen.

e igualmente a la histotecnóloga Diana Milena Rojas Acero.

Guija de Arespacochaga A, Schwendenwein I, Weissenbo"ck H. Retrospective Study of 82 Cases of Canine Lymphoma in Austria based on the Working Formulation and Immunophenotyping. J. Comp. Path. 2007;136:186-192.

Marconato $\mathrm{L}$. The staging and treatment of multicentric high-grade lymphoma in dogs: A review of recent developments and future prospects. The Veterinary Journal. 2011; 188:34-38.

Meyer DJ, Harvey JW. El laboratorio en Medicina Veterinaria, Interpretación y Diagnostico. Apéndice: intervalos de referencia y tablas de conversión, Buenos Aires Argentina, Intermédica, segunda edición, 2000, p 370 .

Meuten D. Tumors of the Urinary System. En: Meuten D. Tumors in Domestical Animals. 4th edit lowa State Press, Blackwell publishers Company. 2002, p.523.

Modiano JF, Breen M, Robert C, Parker HG, Inusah S, Thomas R, Avery PR, Lindblad-Toh K, Ostrander E, Cutter GC, Avery ACDistinct B-Cell and T-Cell Lymphoproliferative Disease Prevalence among Dog Breeds Indicates Heritable Risk. Cancer Res 2005; 65: (13). 
Moore A. S. Environmental causes of cancer in pets. Proceedings of the World Small Animal Veterinary Association Sydney, Australia - 2007.

Moore A. S. What is the best protocol for canine lymphoma?. Proceedings of the World Small Animal Veterinary Association Sydney, Australia - 2007.

Oltra Ferrando M. Médico Especialista en Medicina Oncológica. Hospital “Virgen de los Lirios”. Síndrome anémico y cáncer. Alcoy. Alicante. España 2007.

Ponce F, Magnol JP, Ledieu D, Marchal T, Turinelli V, Chalvet-Monfray K, Fournel-Fleury C.. Prognostic significance of morphological subtypes in canine malignant lymphomas during chemotherapy. The Veterinary Journal. 2004; 16:158-166.

Ramos Vara J. Tumores Hemolinfáticos I. En: Iregui CA, Rey AL, Botero L, editores. Memorias 1. Bogotá, Colombia: Curso Seminario Internacional de Patología Veterinaria. 2008. p. 185.

Raskin RE, Latimer KS, Tvedten H, Leukocyte Disorders. En: Willard M. D, Tvedten H. Small Animal Clinical Diagnosis by Laboratory Methods. Missouri, USA: Saunders 2004;4:84.
Rondon I, Jaramillo H.-Torres. Linfosarcoma Canino, Universidad de los Llanos, Escuela de Medicina Veterinaria y Zootecnia, Villavicencio, Colombia. Rev.MVZCórdoba 2006; 11(2): 844-850

Valli VE, Jacobs RM, Parodi AL. Histogical Classification of Hematopoietic Tumors of Domestic Animals. 2th edit, Washington, DC, volume VIII, 2002

Valli VE, Jacobs RM, Parodi AL, Vernau W, Moore PF. 2002. Histological Classification of Hematopoietic Tumors of Domestic Animals. Second series volume VIII. Armed Forces Institute of Pathology. American Registry of Pathology. Washington, D. C.

Valli V. E. Hematopoietic system. En Jubb, K.; Kennedy, P. \& Palmer, N. Pathology of Domestics animals. Elsevier Saunders, 2007;3:204-206.

Valli VE, San Myint M, Barthel A, Bienzle D, Caswell J, Colbatzky F, Durham A, Ehrhart E. J, Johnson Y, Jones C, Kiupel M, Labelle P, Lester S, Miller M, Moore P, Moroff S, Roccabianca P, Ramos-Vara J, Ross A,. Scase T, Tvedten H, Vernau W. Classification of Canine Malignant Lymphomas According to the World Health Organization Criteria. Vet Pathol 2011; 48(1):198-211 